\title{
EFEKTIVITAS ZEOLIT TERHADAP SERAPAN NITROGEN DAN TINGGI TANAMAN PADA BAWANG MERAH
}

\author{
${ }^{\mathbf{1}}$ Daryono, ${ }^{2}$ Muhamad Hasdar, ${ }^{3}$ Wadli \\ ${ }^{1,2,3}$ Fakultas Sains dan Teknologi, Universitas Muhadi Setiabudi, \\ Brebes, Indonesia \\ E-mail: 1daryonoyono1956@gmail.com²hasdarmuhammad@gmail.com \\ ${ }^{3}$ wadliumus@gmail.com
}

\begin{abstract}
The main objective of this research was to determine the effectiveness of zeolite application on red yam plants using nitrogen uptake and plant height parameters. This study used a randomized block design (RAK) method with a combination of 2 factors, the first factor was the zeolite dose $(0 \mathrm{~kg} / \mathrm{ha}, 4000 \mathrm{~kg} / \mathrm{ha}$ Zeolite, $8000 \mathrm{~kg} / \mathrm{ha}$ ) and the second factor was the shallot variety (Bima Brebes, Super Philip, and the Trident). The size of the plots was $1.8 \mathrm{~m} \times 1 \mathrm{~m}$, the distance between the plots was $30 \mathrm{~cm}$, the distance between replicates was $100 \mathrm{~cm}$ using a spacing of $20 \mathrm{~cm} \times 15 \mathrm{~cm}$. The results of zeolite treatment 4 tonnes / ha on Bima Brebes variety showed the highest nitrogen uptake, namely 17.72. The best plant height was produced using zeolite 8 ton / ha with Bima Brebes variety.
\end{abstract}

Key words: zeolite, shallots, varieties, nitrogen

\section{PENDAHULUAN}

Allium ascalonicum $L$ atau sering disebut tanaman bawang merah merupakan salah satu jenis sayuran rempah yang digunakan sebagai bumbu atau penyedap masakan sehari - hari yang paling populer di masyarakat Indonesia dan terkadang dipergunakan juga sebagai obat tradisional. Komoditi ini merupakan komoditi sayuran unggulan di Indonesia yang telah lama diusahakan oleh para petani secara intensif walaupun belum sepenuhnya menerapkan metode budidaya bawang merah yang benar dan ramah lingkungan. Pada beberapa daerah telah terbentuk sentra- sentra produksi dan sentra pengembangan yang telah relatif lebih maju dalam penerapan teknologi budidaya dan kesesuaian iklimnya (Saleh, 2018).

Di Indonesia terdapat 13 varietas bawang merah unggulan yang direkomendasikan oleh pemerintah untuk digunakan para petani yaitu varietas Super Philip, Bima Brebes, Tinombo, Manjung, Kuning, Maja Cipanas, batu ijo, Kramat 1, Kramat 2, Tiron, Keta Monca, dan Palasa (Wiguna et al., 2013). Peningkatan produksi bawang merah dalam negeri selalu bertujuan untuk memenuhi kebutuhan pasar dalam negeri juga untuk memenuhi permintaan dari luar negeri tetapi dengan meningkatkan kualitas bermutu yang sesuai dengan prosedur operasional standar (SOP) budidaya bawang mearah yang baik dan ramah lingkungan (Good Agriculture Practices) dan ramah terhadap kesehatan petani. Di Indonesia luas lahan tanaman bawang merah seluas 103.063 ha, dengan efektifitas produksi mencapai rata-rata 8,57 ton per ha setiap tahunnya, efekatifitas produksi bawang merah sebanyak 802.810 ton pada setiap tahunnya. Produksi bawang merah antar waktu dan daerah sentra pengembangan sesuai dengan pola tata tanam musiman, sementara permintaan konsumen dan kebutuhan antar waktu cenderung tetap dan merata sepanjang tahun. Fluktuasi produksi inilah yang harus dikelola agar pengaruh 
situasi pasokan daerah sentra produksi dan pengembangannya dengan waktu tanamnya tidak terdapat kesenjangan (Rosyadi et al., 2010).

Produktivitas bawang merah sangat dipengaruhi oleh beberapa faktor penentu diantaranya adalah mutu bibit, varietas, pemupukan yang tepat dan kondisi lingkungan yang sesuai. Kementrian Pertanian telah banyak melepas varietas unggul bawang merah akan tetapi ketersediaan bibit tentu tergantung dari aktivitas industri perbenihan dan pola permintaan para petani yang berusaha tani budidaya bawang merah. Kenyataan dilapangan menunjukkan bahwa petani lebih memilih bibit yang spesifik unggul dilokasi yang mereka budidayakan, khususnya dilokasi pengembangan sentra-sentra produksi (Istina, 2016).

Paramenter kenaikan produksi pertanian biasanya dihadapkan pada rendahnya efisiensi pupuk nitrogen yang dapat dimanfaatkan oleh tanaman. Slow release Fertilizer (SRF) merupakan hasil teknologi berbentuk pupuk nitrogen yang sering digunakan oleh petani (Saleh et al., 2018) namun sabaian besar menggunakan bahan kimia enamel yang sangat menungkinkan meninggalkan bahan residu aktif yang secara akumulatif dapat merusak struktur alami tanah menjadi lebih tandus (Haditya and Sulistyaningsih, 2020), sehingga bahan alami akan cenderung menjadi pilihan seperti zeolit untuk bahan pembuat SRF (Senda et al., 2009).

Zeolit merupakan salah satu jenis batuan mineral alami (Suwardi, 2009) yang banyak terdapat di Indonesia tersebar dibeberapa lokasi Provinsi Jabar, Jateng, Banten, Jatim dan Lampung. Digunakan sebagai bahan SRF didasarkan pada sifat zeolit memiliki KTK tinggi dan kemampuan menjerap ion amonium dengan mengadsorbsi dan melepas secara lambat (Sastiono, 2004). Praktek pemanfaatan mineral zeolit pada tanah sebagai bahan aktif SRF selalu dicampur dengan pupuk urea (Maulinda et al., 2017), yang kemudian dibentuk menjadi granula dengan alat granulasi sehingga memudahkan petani dalam pengaplikasiannya (Hartatik et al., 2020). Proses tersebut akan membentuk efisiensi penyerapan pupuk nitrogen oleh tanaman bawang merah dan sepanjang periode pertumbuhannya akan tersedia nitrogen dalam jumlah yang optimal serta tidak terjadi kelebihan maupun kekurangan ketersediaannya (Alvernia et al., 2018).

Tujuan utama penelitian ini yaitu untuk mengetahui kemampuan aplikasi zeolite pada tanaman bawang merah pada tiga varietas yang sering ditanam oleh petani bawang merah di Kabupaten Brebes, kemudian diukur menggunakan parameter serapan nitrogen tanaman dan tinggi tamanan setiap minggunya.

\section{METODE PENELITIAN}

Penelitian dilakukan di Desa Sengon Kecamatan Kersana pada lahan eks Balai Benih Hortikultura Dinas Pertanian Tanaman Pangan dan Hortikultura Kabupaten Brebes. Dengan tata letak Titik Koordinat adalah : $06^{\circ} \quad 50^{\prime} 83,5^{\prime \prime}$ Lintang Selatan dan $109^{0} 00^{\prime} 16,5^{\prime \prime}$ Bujur Timur, ketinggian \pm 10 meter diatas permukaan laut (dpl) dan derajat keasaman $(\mathrm{pH}) \mathrm{H}_{2} \mathrm{O}: 6,9$ sedangkan $\mathrm{pH} \mathrm{CaCl}_{2}$ : 6,7 cenderung netral yang memiliki kesesuaian agroklimat pertumbuhan bawang merah.

Penelitian ini menggunakan metode percobaan Rancangan Acak Kelompok (RAK) kombinasi dua faktor (Hasdar et al., 2021), perlakuan aplikasi dosis Zeolit digunakan sebagai faktor yang pertama dan perlakuan varietas bawang merah sebagai faktor kedua, ukuran petak adalah $1,8 \mathrm{~m}$ x $1 \mathrm{~m}$ dengan jarak antar petak adalah $30 \mathrm{~cm}$, dan jarak antar ulangan yaitu $100 \mathrm{~cm}$ dengan manggunakan jarak tanam $20 \mathrm{~cm}$ x $15 \mathrm{~cm}$. Nilai yang signifikan atau berbeda nyata akan dilanjutkan dengan uji Duncan untuk mengetahui perbedaan secara spesifik. kombinasi percobaan dibentuk seperti pola perlakuan pada tabel 1 di bawah ini : 
Copyright@UNISBA Blitar, http://ejournal.unisbablitar.ac.id/index.php/viabel

Daryono, Muhamad Hasdar \& Wadli, 2021. Efektivitas Zeolit Terhadap Serapan Nitrogen Dan

Tinggi Tanaman Pada Bawang Merah. Journal Viabel Pertanian. (2021), 15(1) 52-57

Tabel 1. Pola Perlakuan kombinasi Aplikasi zeolit dan Varietas Bawang Merah

\begin{tabular}{cc}
\hline Perlakuan & Kombinasi Zeolit dan Varietas Bawang Merah \\
\hline A & Aplikasi Zeolit $0 \mathrm{~kg} / \mathrm{ha}$ dan varietas Bima Brebes; \\
B & Aplikasi Zeolit $4000 \mathrm{~kg} / \mathrm{ha}$ dan varietas Bima Brebes; \\
C & Aplikasi Zeolit $8000 \mathrm{~kg} / \mathrm{ha}$ dan varietas Bima Brebes; \\
D & Aplikasi Zeolit $0 \mathrm{~kg} / \mathrm{ha}$ dan varietas Super Philip; \\
E & Aplikasi Zeolit $4000 \mathrm{~kg} / \mathrm{ha}$ dan varietas Super Philip; \\
F & Aplikasi Zeolit $8000 \mathrm{~kg} / \mathrm{ha}$ dan varietas Super Philip; \\
G & Aplikasi Zeolit $0 \mathrm{~kg} / \mathrm{ha}$ dan varietas Trisula; \\
H & Aplikasi Zeolit $4000 \mathrm{~kg} / \mathrm{ha}$ dan varietas Trisula; dan \\
I & Aplikasi Zeolit $8000 \mathrm{~kg} / \mathrm{ha}$ dan varietas Trisula. \\
\hline
\end{tabular}

\section{HASIL DAN PEMBAHASAN}

\section{a. Serapan Nitrogen}

Kemampuan tanaman dalam menyerap nitrogen menjadi salah satu tolak ukur keberhasilan penggunaan pupuk atau pembenah tanah lainnya dalam pertumbuhan dan produksi tanaman (Gonggo $\mathrm{M}$ et al., 2006). Unsur nitrogen sangat berperan dalam fisiologi tanaman khususnya untuk pertumbuhan dan produksi tamanan (Amir et al., 2012). Data hasil analisis statistik dari pengaruh pengunaan dosis zeolit yang diaplikasikan pada beberapa varietas bawang merah memberikan pengaruh yang signifikan terhadap kemampuan serapan nitrogen dari tanaman bawang merah, dan hasil statistik analisis ragam disajikan pada tabel 2 dibawah ini.

Tabel 2. Efektivitas Aplikasi Zeolit Pada Varietas Bawang Merah Terhadap Serapan Nitrogen

\begin{tabular}{lc}
\hline \multicolumn{1}{c}{ Perlakuan } & Serapan Nitrogen (\%) \\
\hline A (Zeolit 0 ton/ha dan Varietas Bima Brebes) & $16,41 \mathrm{~d}$ \\
B (Zeolit 4 ton/ha dan Varietas Bima Brebes) & $\mathbf{1 7 , 7 2 ~ e ~}$ \\
C (Zeolit 8 ton/ha dan Varietas Bima Brebes) & $15,06 \mathrm{~d}$ \\
D (Zeolit 0 ton/ha dan Varietas Super Philip) & $10,68 \mathrm{a}$ \\
E (Zeolit 4 ton/ha dan Varietas Super Philip) & $12,43 \mathrm{c}$ \\
F (Zeolit 8 ton/ha dan Varietas Super Philip) & $11,23 \mathrm{~b}$ \\
G (Zeolit 0 ton/ha dan Varietas Trisula) & $13,33 \mathrm{c}$ \\
H (Zeolit 4 ton/ha dan Varietas Trisula) & $14,39 \mathrm{~d}$ \\
I (Zeolit 8 ton/ha dan Varietas Trisula) & $12,89 \mathrm{c}$ \\
\hline
\end{tabular}

Keterangan : Angka rata- rata yang diikuti huruf yang berbeda menyatakan signifikan

Berdasarkan informasi hasil analis ststistik pada tabel 2 dapat dijelaskan terjadi serapan nitrogen yang sangat maksimal pada perlakuan varietas Bima Brebes disusul varietas Trisula dan varietas Super Philip. Juga terlihat perbedaan yang signifikan dari penggunaan zeolite pada varietas Bima Brebes. Pengaruh dosis zeolit terhadap serapan nitrogen terbaik pada perlakuan B (Zeolit 4 ton/ha dan varietas Bima Brebes). Penambahan zeolit akan meningkatkan efisiensi pemupukan, kation-kation $\mathrm{NH} 4+$ dan $\mathrm{K}+$ akan terikat pada kerangka zeolit dan kation ini kemudian akan dapat dilepaskan secara perlahan-lahan disekitar daerah perakaran untuk diserap oleh tanaman (Agung et al., 2011). 


\section{b. Tinggi Tanaman $(\mathbf{C m})$}

Tinggi tanaman menjadi paramemter penting untuk mengetahui efektifitas perlakuan zeolit pada bawang merah berdasarkan umur tamanan. Data pengamatan serapan nitrogen pada tanaman bawang merah (3 sampai 5 MST) disajikan pada tabel 3 dibawah ini.

Tabel 3. Efektivitas Aplikasi Zeolit pada Varietas Bawang Merah Terhadap Tinggi Tanaman (cm) Umur 3, 4, dan 5 MST (minggu setelah tanam)

\begin{tabular}{llll}
\hline \multirow{2}{*}{ Perlakuan } & \multicolumn{3}{c}{ Tinggi Tanaman (cm) } \\
\cline { 2 - 4 } & 3 MST & 4 MST & 5 MST \\
\hline A (Zeolit 0 ton/ha dan Varietas Bima Brebes) & $29,12 \mathrm{~b}$ & $30,90 \mathrm{~b}$ & $33,17 \mathrm{~b}$ \\
B (Zeolit 4 ton/ha dan Varietas Bima Brebes) & $28,75 \mathrm{~b}$ & $31,88 \mathrm{~b}$ & $33,92 \mathrm{~b}$ \\
C (Zeolit 8 ton/ha dan Varietas Bima Brebes) & $29,47 \mathrm{~b}$ & $31,78 \mathrm{~b}$ & $35,45 \mathrm{~b}$ \\
D (Zeolit 0 ton/ha dan Varietas Super Philip) & $23,92 \mathrm{a}$ & $25,80 \mathrm{a}$ & $27,82 \mathrm{a}$ \\
E (Zeolit 4 ton/ha dan Varietas Super Philip) & $23,32 \mathrm{a}$ & $24,70 \mathrm{a}$ & $27,95 \mathrm{a}$ \\
F (Zeolit 8 ton/ha dan Varietas Super Philip) & $24,48 \mathrm{a}$ & $26,23 \mathrm{a}$ & $28,78 \mathrm{a}$ \\
G (Zeolit 0 ton/ha dan Varietas Trisula) & $24,28 \mathrm{a}$ & $25,28 \mathrm{a}$ & $27,52 \mathrm{a}$ \\
H (Zeolit 4 ton/ha dan Varietas Trisula) & $24,97 \mathrm{a}$ & $26,87 \mathrm{a}$ & $28,32 \mathrm{a}$ \\
I (Zeolit 8 ton/ha dan Varietas Trisula) & $24,72 \mathrm{a}$ & $26,92 \mathrm{a}$ & $28,95 \mathrm{a}$ \\
\hline
\end{tabular}

Keterangan : Angka rata- rata yang diikuti huruf yang berbeda menyatakan signifikan

Berdasarkan data statistik yang disajikan pada tabel 3 dapat diketahui bahwa pengaruh zeolit terhadap rata- rata tinggi tanaman pada umur 3,4 dan 5 MST menunjukkan pengaruh yang nyata untuk semua varietas. Jenis atau varietas tanaman yang menghasilkan tanaman paling tinggi adalah varietas Bima Brebes, telah menunjukkan hasil pengamatan tertinggi pada umur 3,4 maupun 5 MST. Tanaman bawang merah varietas Bima Brebes bisa mempunyai rata- rata yang paling tinggi dibandingkan dengan varietas Super Philip maupun varietas lainnya. (Upe and Sau, 2018). Pengaplikasian zeolit sebagai mineral bahan pembenah tanah (Al-Jabri, 2010) yang diharapkan dapat mengubah lahan kritis menjadi produktif ternyata mampu meningkatkan KTK sampai diatas $100 \mathrm{cmol} / \mathrm{kg}$ dengan dosis 5 ton perha (Cairo et al., 2018), pemberian zeolit sebanyak 3-6 ton/ha dapat menyebabkan akumulasi unsur hara $\mathrm{N}$ menjadi dua kali lipat lebih tinggi dibandingkan dengan kontrol (Sangeetha and Baskar, 2016).

\section{KESIMPULAN}

Penggunan zeolit pada beberapa varietas bawang merah memberikan pengaruh yang nyata terhadap serapan nitrogen, dimana hasil serapan nitrogen tertinggi pada perlakuan B (zeolit 4 ton/ha dan varietas Bima Brebes) sebesar 17,2\%. Penggunaan zeolite juga memberikan pengaruh yang nyata pada pertumbuhan tamanan bawang merah, dimana tinggi tanaman yang signifikan terlihat pada perlakuan $\mathrm{C}$ (Zeolit 8 ton/ha dan Varietas Bima Brebes) dengan kenaikan tinggi tamanan terbaik setiap minggunya.

\section{DAFTAR PUSTAKA}

Agung, A., Syamsiyah, J., Riyanto, D., Minardi, S., 2011. Pengaruh pupuk zeolit dan kalium terhadap ketersediaan dan serapan K di lahan berpasir pantai Kulonprogo , Yogyakarta The effect of zeolite and $\mathrm{K}$ fertilizer to availability and $\mathrm{K}$ uptake at 
seashore sandy land of. Bonorowo Wetl. 1, 1-7.

Al-Jabri, M., 2010. Penggunaan Mineral Zeolit Sebagai Pembenah Tanah Pertanian Dalam Hubungan Dengan Standardisasinya Dan Peningkatan Produksi Tanaman Pangan. J. Zeolit Indones. 9, 1-12.

Alvernia, P., Minardi, S., Suntoro, 2018. Zeolite and Organic Fertilizer Application to The Improvement OF Available P and Soybean (glycine max L) Seed Yield in Alfisols. J. Soil Sci. Agroclimatol. 14, 83-89.

Amir, L., Sari, A.P., Hiola, S.F., Jumadi, O., 2012. Ketersediaan Nitrogen Tanah dan Pertumbuhan Tanaman Bayam ( Amaranthus tricolor L .) yang Diperlakukan dengan Pemberian Pupuk Kompos Azolla The Availability of Nitrogen Soil and Growth of Spinach ( Amaranthus tricolor L .) Treated with the Azolla Compost. J. Sainsmat 1, 167-180.

Cairo, P.C., Armas, J.M. De, Artiles, P.T., Martin, B.D., Carrazana, R.J., Lopez, O.R., 2018. Effects of zeolite and organic fertilizers on soil quality and yield of sugarcane Effects of zeolite and organic fertilizers on soil quality and yield of sugarcane. Aust. J. Crop Sci. 06, 733-738.

Gonggo M, B., Hasanudin, Indriani, Y., 2006. Peran Pupuk N Dan P Terhadap Serapan N, Efisiensi N Dan Hasil Tanaman Jahe Di Bawah Tegakan Tanaman Karet. J. Ilmu-Ilmu Pertan. Indones. 8, 61-68.

Haditya, E.B., Sulistyaningsih, T., 2020. Penggunaan Zeolit A Termodifikasi HDTMA sebagai Slow Release Urea Fertilizer. Indones. J. Chem. Sci. 9, 31-36.

Hartatik, W., Mardliyati, E., Wibowo, H., Sukarto, A., Yusron, 2020. Formulasi dan Pola Kelarutan N Pupuk Urea-Zeolit Lepas Lambat. J. Tanah dan Iklim 44, 61-70.

Hasdar, M., Wadli, Meilani, D., 2021. Rancangan Acak Lengkap Dan Rancangan Acak Kelompok Pada pH Gelatin Kulit Domba Dengan Pretreatment Larutan NaOH. J. Technol. Food Process. 1, 17-23.

Istina, I.N., 2016. Peningkatan Produksi Bawang Merah Melalui Teknik Pemupukan NPK. J. Agro 3, 36-42.

Maulinda, R., Damayani, M., Joy, B., 2017. Pengaruh Pupuk Kombinasi Urea - Zeolit Arang Aktif (UZAA) terhadap pH, Eh, Amonium dan Nitrat pada Tanah Sawah Rancaekek, Kabupaten Bandung Restiana. Soilrens 15, 1-8.

Rosyadi, I., Achmad, N., Triyono, 2010. Meningkatkan Efisiensi dan Profitabilitas Pada Usaha Tani Bawang Merah di Kabupaten Brebes. Warta 13, 65-76.

Saleh, I., 2018. Karakteristik dan Viabilitas Bibit Bawang Merah Pada Waktu Panen Berbeda. J. Hexagro 2, 30-35.

Saleh, M., Zulmanwardi, Pasanda, O.S., 2018. Pembuatan Pupuk SRF (Slow Release Fertilizer) Dengan Menggunakan Polimer Amilum. In: Prosiding Seminar Hasil Penelitian (SNP2M). pp. 80-85.

Sangeetha, C., Baskar, P., 2016. Zeolite and its potential uses in agriculture: A critical review. Agric. Rev. 37, 101-108.

Sastiono, A., 2004. Pemanfaatan Zeolit di Bidang Pertanian. J. Zeolit Indones. 3, 36-41.

Senda, S.P., Handogo, R., Roesyadi, A., Sumaryono, W., 2009. Mixing Urea and Zeolite 
Daryono, Muhamad Hasdar \& Wadli, 2021. Efektivitas Zeolit Terhadap Serapan Nitrogen Dan Tinggi Tanaman Pada Bawang Merah. Journal Viabel Pertanian. (2021), 15(1) 52-57

for Slow Release Fertilizer using Orbiting Screw Mixer. IPTEK J. Technol. Sci. $20,148-154$.

Suwardi, 2009. Teknik Aplikasi Zeolit di Bidang Pertanian Sebagai Bahan Pembenah Tanah. J. Zeolit Indones. 8, 33-38.

Upe, A., Sau, T., 2018. Adaptasi Keberagaman Varietas Terhadap Pertumbuhan dan Produksi Pada Wilayah Marginal Pertanaman Bawang Merah (Allium ascalanicum L.). J. TABARO 2, 172-177.

Wiguna, G., Hidayat, I., Azmi, C., 2013. Perbaikan Teknologi Produksi Benih Bawang Merah Melalui Pengaturan Pemupukan, Densitas, dan Varietas ( Improvement of Shallots Seed Production Technology by Setting Fertilization, Density, and Variety ). J. Hortik. 23, 137-142. 